\title{
Shouldn't enantiomeric purity be included in the "minimum information about a bioactive entity'?
}

\section{Giovanni Lentini}

Integrating knowledge from a variety of published reports is a crucial aspect in the development of bioactive entities. Unfortunately, the analysis of the enormous body of items of information reported in the literature for biologically active compounds is hampered by the lack of both uniformity and completeness of data. In order to overcome the difficulties arising from the heterogeneity and defectiveness of data formats, 26 scholars from data resource providers, pharmaceutical companies and academic groups have recently proposed a formal list of the items of information that should be provided when describing the preparation and biological evaluation of compounds (Minimum information about a bioactive entity (MIABE). Nature Rev. Drug Discov. 10, 661-669 (2011)) $)^{1}$. By following this checklist, researchers would be able to offer the 'minimum information about a bioactive entity' (MIABE) to the international scientific community for each compound to be published.

Despite their commendable efforts towards exhaustiveness, in the compilation of the MIABE guidelines the authors overlooked an aspect that is crucial, in my opinion, for correctly interpreting biological data obtained from studies on chiral compounds: enantiomeric purity. Since Barlow's ${ }^{2}$ studies were published, the stereochemical purity of chiral compounds has been assumed to be a mandatory aspect to consider when evaluating the activity of single enantiomeric forms of drugs if one enantiomer has an appreciably higher biological activity than the other. In these cases, even low percentages of the contaminant enantiomer may heavily influence the activity of the principal enantiomer ${ }^{3}$. Furthermore, and in particular, when in vivo activities are considered, the degree of enantiomeric purity may influence both qualitatively and quantitatively the biological outcome, often in an unpredictable way ${ }^{4}$. Thus, without specification of enantiomeric purity data, the biological activity data reported in the MIABE guidelines for many homochiral compounds could be biased and could expose researchers to potential pitfalls associated with compound chirality ${ }^{5,6}$.

$$
\begin{array}{r}
\text { Giovanni Lentini is at the Facoltà di Farmacia, } \\
\text { Via Orabona, 4, } 70126 \text { Bari, Italy. } \\
\text { e-mail: glentini@farmchim.uniba.it } \\
\text { doi:10.1038/nrd3503-c1 }
\end{array}
$$

1. Orchard, S. et al. Minimum information about a bioactive entity (MIABE). Nature Rev. Drug Discov. 10, 661-669 (2011).

2. Barlow, R. B., Franks, F. M. \& Pearson, J. D. M. The relation between biological activity and the degree of resolution of optical isomers. J. Pharm. Pharmacol. 24, 753-761 (1972).

3. Waldeck, B. Biological significance of the enantiomeric purity of drugs. Chirality 5, 350-355 (1993).

4. Testa, B. \& Trager, W. F. Racemates versus enantiomers in drug development: dogmatism or pragmatism? Chirality 2, 129-133 (1990).

5. Ariens, E. J. Chirality in bioactive agents and its pitfalls. Trends Pharmacol. Sci. 7, 200-205 (1986).

6. Jamali, F., Mehvar, R. \& Pasutto, F. M.

Enantioselective aspects of drug action and disposition: therapeutic pitfalls. J. Pharm. Sci. 78 695-715 (1989).

Competing financial interests

The author declares no competing financial interests. 